\title{
Regional Characteristics of Interannual Variability of Summer Rainfall in the Maritime Continent and Their Related Anomalous Circulation Patterns
}

\author{
QI XU \\ Key Laboratory of Meteorological Disaster, Ministry of Education/Joint International Research Laboratory of Climate and \\ Environment Change/Collaborative Innovation Center on Forecast and Evaluation of Meteorological Disasters, Nanjing University of \\ Information Science and Technology, and Jiangsu Climate Center, Nanjing, China \\ ZhAOYONG GUAN, DACHAO Jin, AND DingZHU HU \\ Key Laboratory of Meteorological Disaster, Ministry of Education/Joint International Research Laboratory of Climate and \\ Environment Change/Collaborative Innovation Center on Forecast and Evaluation of Meteorological Disasters, Nanjing University \\ of Information Science and Technology, Nanjing, China
}

(Manuscript received 30 July 2018, in final form 11 April 2019)

\begin{abstract}
Using the NCEP-NCAR reanalysis and Global Precipitation Climatology Project monthly rainfall, we have investigated the regional features of interannual variations of rainfall in the Maritime Continent (MC) and their related anomalous atmospheric circulation patterns during boreal summer by employing the rotated empirical orthogonal function (REOF) analysis. Our results demonstrate that the rainfall variabilities in the $\mathrm{MC}$ are of very striking regional characteristics. The $\mathrm{MC}$ is divided into four independent subregions on the basis of the leading REOF modes; these subregions are located in central-eastern Indonesia (subregion I), the oceanic area to the west of Indonesia (subregion II $+\mathrm{V}$ ), the part of the warm pool in the equatorial western Pacific Ocean (subregion III), and Guam (subregion IV+VI).The anomalous precipitation in different subregions exhibits different variation periodicities, which are associated with different circulation patterns as a result of atmospheric response to different sea surface temperature anomaly (SSTA) patterns in the tropical Indo-Pacific sector. It is found that rainfall anomalies in subregion I are induced by the Pacific ENSO, whereas those in subregion II $+\mathrm{V}$ are dominated by a triple SSTA pattern with positive correlations in the MC and negative correlation centers in the tropical Pacific and tropical Indian Ocean. Rainfall anomalies in subregion III mainly resulted from an SSTA pattern with negative correlations in the eastern MC and positive correlations in the western equatorial Pacific east of the MC. A horseshoe SSTA pattern in the central Pacific is found to affect the precipitation anomalies in subregion IV+VI. All of the results of this study are helpful for us to better understand both the climate variations in the MC and monsoon variations in East Asia.
\end{abstract}

\section{Introduction}

The "Maritime Continent" (MC) region, roughly defined over $10^{\circ} \mathrm{S}-20^{\circ} \mathrm{N}, 90^{\circ}-150^{\circ} \mathrm{E}$ by Ramage (1968), is located at the transitional zone between the Indian and Pacific Oceans and between Asia and Australia and is characterized by complex terrain with many islands and shallow seas. This region plays a critical role in global climate variations (Ramage 1968; Neale and Slingo 2003). More than this, it is also influenced by multiple weather and climate phenomena on different time scales (e.g., Klein et al. 1999; Lau and Nath 2003; McBride

Corresponding author: Zhaoyong Guan, guanzy@nuist.edu.cn; Qi Xu, xqaaron@163.com et al. 2003; Dayem et al. 2007; Kug et al. 2009; Weng et al. 2009; Zhang et al. 2010; Li 2014; Kim and Ha 2015; Jin et al. 2016).

The precipitation in the MC varies on different time scales. Climatologically, total precipitation in the $\mathrm{MC}$ in the Northern Hemisphere summer is concentrated to the north because of the active intertropical convergence zone in the region north of the equator. However, precipitation is not uniformly distributed zonally in this region because of more vigorous convections over the land than over the sea surface (Qian 2008). Associated with topography, it is found that there are significant diurnal cycles of convection in the MC: two diurnal peaks are detected in Indochina, Sumatra, and the South China Sea (Mori et al. 2004; Teo et al. 2011). Distributions of large interannual 
variability of precipitation look different; it occurs to the south of the MC (Song et al. 2011) during boreal summer.

The variations of precipitation in the MC are affected by many kinds of signals from the surrounding regions of the MC. For example, the MJO in the Indian Ocean propagates eastward and consequently may affect the precipitation in the western MC, which is different from that in other parts of the MC region influenced by topography (Madden and Julian 1972; Zhang 2005; Wu and Hsu 2009; Li 2014). El Niño-Southern Oscillation (ENSO) is the strongest interannual signal in equatorial Pacific, which has a large impact on precipitation in Maluku in central Indonesia (Xu and Guan 2017). The anomalous convection in the $\mathrm{MC}$ is also a pit stop for transferring the ENSO impacts to Indian summer monsoon (e.g., Ashok et al. 2004). The Indian Ocean dipole (IOD) also affects the precipitation variation in the MC; the largest correlation between IOD and precipitation is found nearby Java (Saji et al. 1999; Sukresno 2010). It is also found that there exist close relationships between the high pressure system across Australia and precipitation in the southern MC (Chen and Guan 2017), between the heat source in the Bay of Bengal and summer monsoon outbreak with precipitation in the South China Sea (Liu et al. 2003), and between changes in the western Pacific warm pool and precipitation in the northeastern MC (Dayem et al. 2007).

The anomalous forcing induced by precipitation anomalies in the MC can affect climate variability in East Asia. When summer convective activity intensifies in the Philippines, which lead to above-normal precipitation there, the positive heating anomalies are generated, triggering the northeastward propagation of quasigeostrophic planetary waves, leading to the formation of the East Asian Pacific (EAP)/Pacific-Japan (PJ) teleconnection pattern in East Asia and North America (Huang and Li 1987; Nitta 1987). As a result, the western Pacific subtropical high shifts northward in the summer. More than these, it is found that the anomalous convergence and divergence in the MC played a critical role in the occurrence of the extreme drought event occurred in the winter-spring of 2011-12 in the Yangtze River valley (Jin et al. 2013). It is also found that when the summer convection is weaker than normal in both the Bay of Bengal and the monsoon trough region in the South China Sea, the convection is abnormally strong in Indonesia on interannual time scales (Song et al. 2011). Meanwhile, the positive precipitation anomalies occur in the middle and upper reaches of the Yangtze River valley and in areas to its north.

The above studies indicate that there exist large differences in anomalous summer precipitation over different regions of $\mathrm{MC}$, and these differences are associated with tropical ocean forcings and climate variability in East Asia.
To further understand the characteristics of summer precipitation variability in the $\mathrm{MC}$, it is essential to divide the MC into subregions based on the characteristics of precipitation variability in the MC, and to explore the mechanisms of precipitation anomalies in these different regions. Thereby, the rotated empirical orthogonal function (REOF) (Horel 1981; Richman 1981, 1986; Jin et al. 2015) is performed in this study to divide the MC into several subregions that have distinct regional characteristics of interannual variability of precipitation. The different anomalous circulation patterns in association with these regional anomalous precipitation patterns are also investigated. All the results in the present study are beneficial to deepen our understandings of the role and mechanisms of the precipitation variations in the MC in the formation of climate anomalies in the Indo-Pacific sector.

\section{Data and method}

\section{a. Data}

The NCEP2 reanalysis product (Kanamitsu et al. 2002) was used in this study. Monthly mean winds, air temperature, surface pressure, sea surface temperature (SST), and outgoing longwave radiation in the boreal summer during 1979-2013 were extracted from the NCEP2 reanalysis product, which is a gridded dataset with horizontal resolution of $2.5^{\circ} \times 2.5^{\circ}$. The 2 -m temperatures in a global Gaussian grid were also used. Precipitation was extracted from GPCP (Adler et al. 2003) for the same period. Summer refers to June-September.

\section{b. Method}

REOF (Horel 1981; Richman 1981, 1986) is employed in this study to divide the MC region into subregions in terms of precipitation variability. Morlet wavelet analysis (Torrence and Compo 1998) is applied to reveal the periodicities of time series of precipitation. Composite and correlation analyses are used to investigate the relationship between precipitation anomalies and other physical quantities. The horizontal component of Rossby wave activity fluxes (WAF) proposed by Takaya and Nakamura (2001) are calculated to diagnose the wave energy propagations.

\section{Spatial patterns of summer precipitation in the Maritime Continent}

\section{a. Subregions identified by using the REOF modes}

Empirical orthogonal function (EOF) decomposition is performed of the time series of normalized summer precipitation anomalies during 1979-2013 in the MC. The leading 35 eigenvectors are obtained, which account 

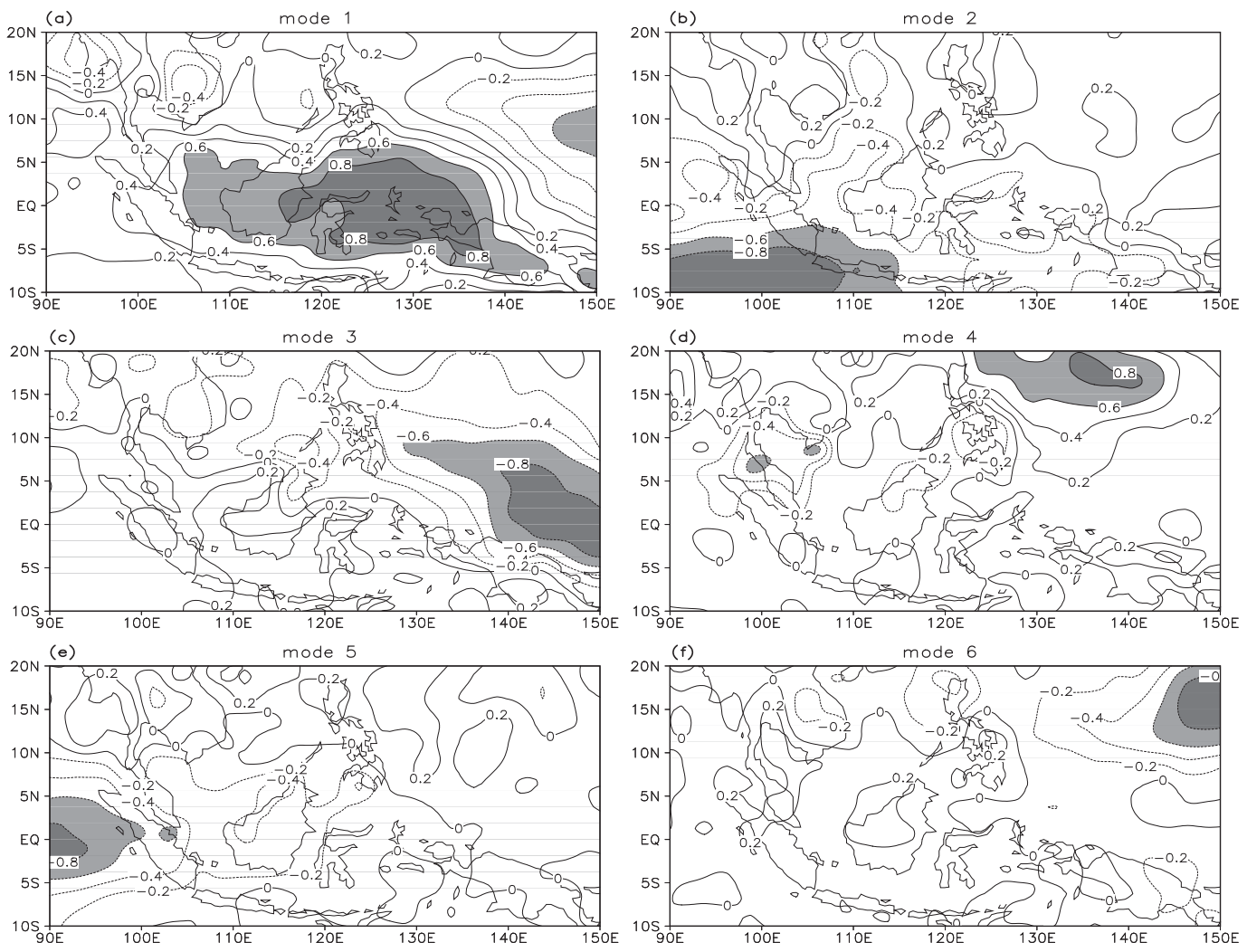

FIG. 1. The (a) first, (b) second, (c) third, (d) fourth, (e) fifth, and (f) sixth leading REOF modes obtained after rotation of the leading 35 EOF eigenvectors of precipitation anomalies during 1979-2013. Shaded areas indicate that the absolute values of the contours are greater than 0.6.

for more than $99 \%$ of the total variance. The 35 eigenvectors are then rotated, and six leading modes that make relative large contributions to the total variance are obtained. The six REOF modes explain $56 \%$ of the total variance; they are sequenced according to their contributions to the total variance from large to small (Fig. 1). The first mode explains $17.39 \%$ of the total variance, the second mode accounts for $11.55 \%$ of the total variance, and the third, fourth, fifth, and sixth modes explain $9.58 \%$, $6.57 \%, 6.09 \%$, and $4.80 \%$ of the total variance, respectively. Based on distributions of these high loading eigenvectors (the absolute values of the contours equal to or larger than 0.8 ) that correspond to the six leading modes of precipitation, six subregions or key precipitation areas in the MC are identified (Fig. 2). These key areas are central-eastern Indonesia (subregion I), the oceanic area to the east of Java (subregion II), the warm-pool area in the equatorial western Pacific (subregion III), the oceanic area to the northeast of the Philippines (subregion IV), the oceanic area to the west of Sumatra Island (subregion $\mathrm{V})$, and the warm-pool area in the northwest Pacific (subregion VI). These six subregions are listed in Table 1 with the roughly defined geographical positions.
Time series of precipitation $P_{i}$ averaged over each individual subregion (Fig. 2) are highly correlated with time series of coefficients $R_{i}$ of the corresponding REOF eigenvectors. The correlation coefficients as seen in Table 2 are $r\left(R_{1}, P_{1}\right)=0.97, r\left(R_{2}, P_{2}\right)=0.96, r\left(R_{3}, P_{3}\right)=$ $0.92, r\left(R_{4}, P_{4}\right)=0.87, r\left(R_{5}, P_{5}\right)=0.84$, and $r\left(R_{6}, P_{6}\right)=$ 0.92 . The variance of precipitation $P_{i}$ in the $i$ th subregion can be largely explained by $R_{i}$. The smallest correlation coefficient is found to be between $P_{5}$ and $R_{5}$, which still explains $70.56 \%$ of total variance of $P_{5}$ in the oceanic area to the west of Sumatra Island.

\section{$b$. Independence of precipitation variations among subregions}

To verify the independence of precipitation in each subregion, correlations between time series of areaaveraged precipitation are calculated. It is found that the correlation coefficient between $P_{2}$ and $P_{5}$ is up to 0.54 , and that between $P_{4}$ and $P_{6}$ reaches 0.48 . These two correlation coefficients look to be large and significant although the correlations between time series of coefficients of REOF mode $R_{2}$ and that of $R_{5}$, and that between $R_{4}$ and $R_{6}$ are zeroes. The significant 


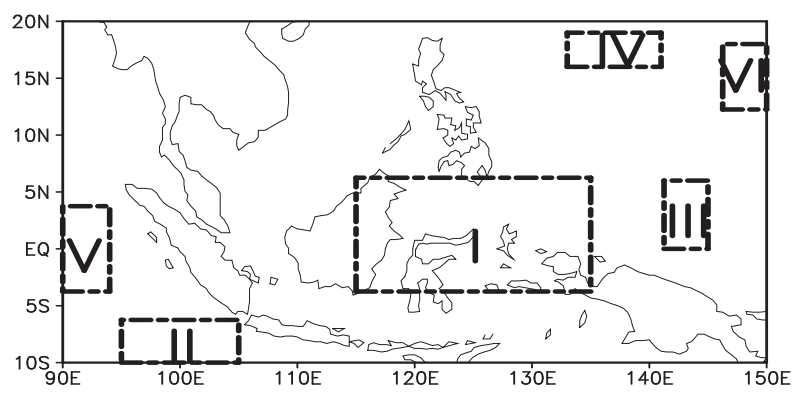

FIG. 2. The six key precipitation areas in the MC as identified by the leading six REOF modes.

correlation between $P_{2}$ and $P_{5}$ is possibly due to the fact that there are in-phase components of precipitation variations in $P_{2}$ and $P_{5}$. It works out that $R_{2}$ can explain $92.16 \%$ of total variance of $P_{2}$, whereas $R_{5}$ explains $70.56 \%$ of total variance of $P_{5}$. This means that the component with $29.44 \%$ of variance of $P_{5}$ is correlated with $P_{2}$. Technically, subregion II and subregion $\mathrm{V}$ are so close to each other (Fig. 2) that some in-phase components of precipitation variations in subregion II and subregion $\mathrm{V}$ are not well separated. Of course, the ENSO or IOD signal can also affect the precipitation anomalies in both subregion II and subregion V (subregion IV and subregion VI), which make the rainfall anomalies in subregion II (subregion IV) significantly correlated with those in subregion V (subregion VI). That is, after the subregions are divided based on precipitation, $P_{i}$ over each subregion includes not only the component represented by $R_{i}$ but also other components that are correlated among different subregions. For convenience, we hereinafter refer to the anomalous precipitation pattern over subregion $\mathrm{I}$ as the type-I pattern of precipitation anomalies. This is similar for other subregions; thus, we have six types of precipitation patterns: type I, type II, type III, type IV, type V, and type VI.

Considering the above fact that similar precipitation variations may exist between those proximity subregions among which the area-averaged precipitation anomalies are significantly correlated with each other, here we combine subregions II and V together, that is, subregion II $+\mathrm{V}$, over which the new time series of

TABLE 1. Geographical areas of each subregion.

\begin{tabular}{lc}
\hline \hline Sub-regions & Geographical area \\
\hline Sub-region I & $115^{\circ}-135^{\circ} \mathrm{E}, 3.75^{\circ} \mathrm{S}-6.25^{\circ} \mathrm{N}$ \\
Sub-region II & $95^{\circ}-105^{\circ} \mathrm{E}, 10^{\circ}-6.25^{\circ} \mathrm{S}$ \\
Sub-region III & $141.25^{\circ}-145^{\circ} \mathrm{E}, \mathrm{EQ}-6^{\circ} \mathrm{N}$ \\
Sub-region IV & $133^{\circ}-141^{\circ} \mathrm{E}, 16^{\circ}-19^{\circ} \mathrm{N}$ \\
Sub-region V & $90^{\circ}-94^{\circ} \mathrm{E}, 3.75^{\circ} \mathrm{S}-3.75^{\circ} \mathrm{N}$ \\
Sub-region VI & $146.25^{\circ}-150^{\circ} \mathrm{E}, 12.25^{\circ}-18^{\circ} \mathrm{N}$ \\
\hline
\end{tabular}

TABLE 2. Correlation coefficients between time series of areaaveraged summer precipitation $P_{i}$ and time series of coefficients $R_{i}$ of the corresponding REOF eigenvector for each subregion. The critical value of the absolute of correlation coefficient at $95 \%$ confidence is found to be 0.33 . Those values above 0.33 in the table are denoted by asterisks.

\begin{tabular}{lrrrrrr}
\hline \hline Time series & \multicolumn{1}{c}{$R_{1}$} & \multicolumn{1}{c}{$R_{2}$} & \multicolumn{1}{c}{$R_{3}$} & \multicolumn{1}{c}{$R_{4}$} & \multicolumn{1}{c}{$R_{5}$} & \multicolumn{1}{c}{$R_{6}$} \\
\hline$P_{1}$ & $0.97^{*}$ & -0.15 & 0.00 & 0.02 & -0.13 & 0.03 \\
$P_{2}$ & 0.14 & $-0.96^{*}$ & 0.10 & -0.05 & -0.10 & 0.02 \\
$P_{3}$ & -0.08 & 0.20 & $-0.92^{*}$ & 0.08 & 0.08 & 0.02 \\
$P_{4}$ & 0.06 & 0.05 & -0.28 & $0.87^{*}$ & 0.00 & -0.23 \\
$P_{5}$ & 0.26 & -0.40 & 0.13 & -0.09 & $-0.84^{*}$ & 0.07 \\
$P_{6}$ & -0.20 & 0.06 & -0.11 & 0.27 & 0.06 & $-0.92^{*}$ \\
\hline
\end{tabular}

precipitation anomalies are obtained as $P_{2+5}$. Similarly, precipitation anomalies over subregions IV and VI are also combined, yielding $P_{4+6}$. Then, subregion I is located at central-eastern Indonesia, subregion $\mathrm{II}+\mathrm{V}$ is situated over the oceanic area to the west of Indonesia, subregion III is within the warm pool of the equatorial western Pacific, and subregion IV+VI is located at Guam. Correlations among the anomalous precipitation time series of the above four subregions are listed in Table 3. Although the correlation coefficient between certain subregions is still above $95 \%$ confidence level, the variance explained is low enough so that precipitation in each subregion is approximately independent of that in all other subregions. This result indicates that it is reasonable to divide $\mathrm{MC}$ at least into the four subregions on the basis of the regional characteristics of precipitation anomalies.

\section{Variations of precipitation and related circulations}

\section{a. Temporal evolutions of precipitation over different subregions}

The anomalous precipitation variations are apparently different from one subregion to another. Type-I anomalous precipitation (Fig. 3a) is mostly confined in region of Indonesian archipelagos, dominated by anomalies of local convective activities. This type of

TABLE 3. Correlation coefficients between precipitation series after the combinations. The critical value for correlation coefficient at $95 \%$ confidence interval is found to be 0.33 . Values above the critical value are denoted by an asterisk.

\begin{tabular}{lclcc}
\hline \hline Time series & $P_{1}$ & $P_{2+5}$ & $P_{3}$ & $P_{4+6}$ \\
\hline$P_{1}$ & 1 & $0.37^{*}$ & -0.12 & -0.09 \\
$P_{2+5}$ & & 1 & $-0.33^{*}$ & -0.20 \\
$P_{3}$ & & & 1 & 0.30 \\
$P_{4+6}$ & & & & 1 \\
\hline
\end{tabular}



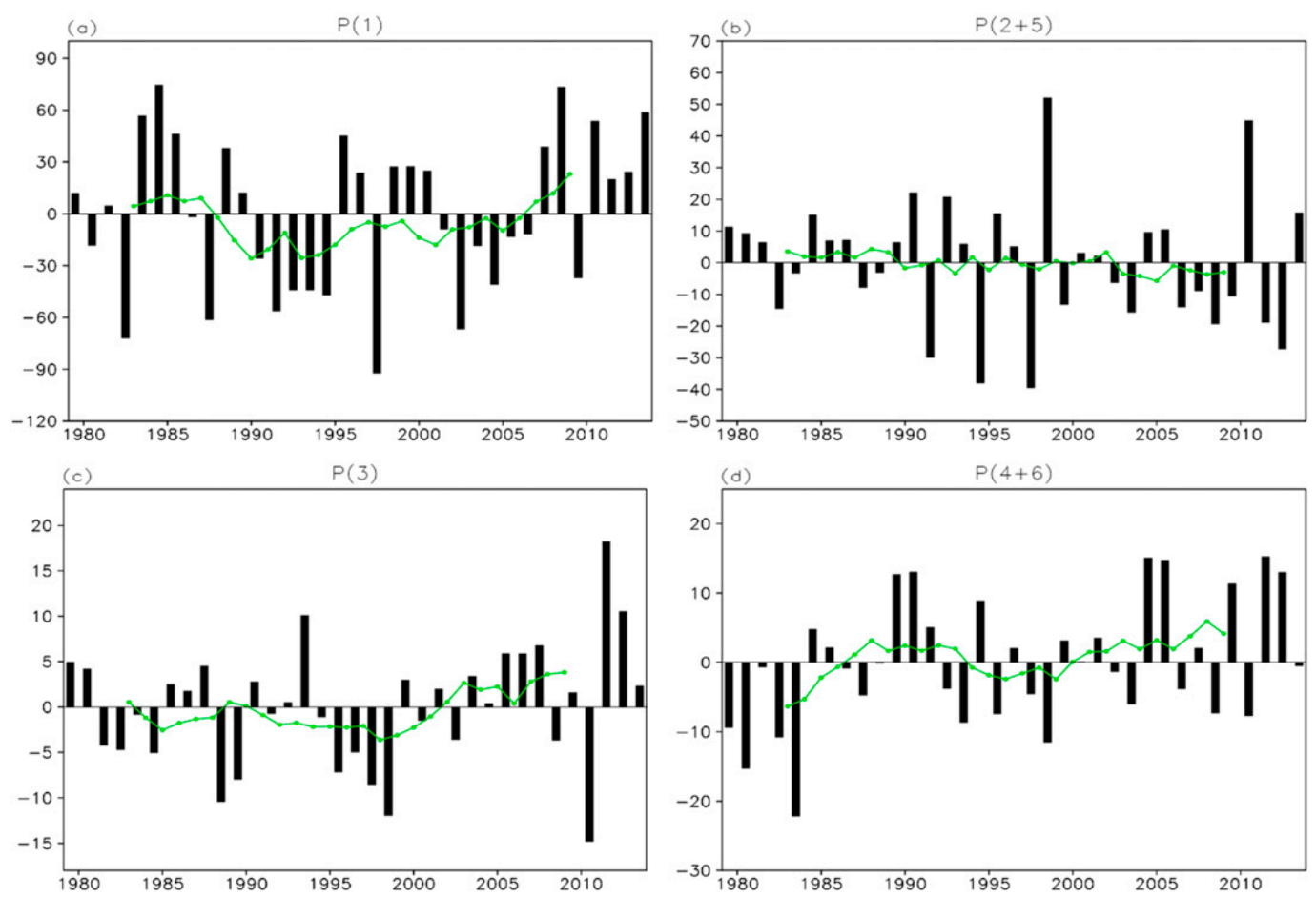

FIG. 3. Time series of summer precipitation anomalies (bars) in the MC for (a) type I, (b) type II+V, (c) type III, and (d) type IV+VI. The curves in green represent 9-yr moving averages for each time series.

anomalous precipitation pattern is strongly related to central Pacific-type ENSO/El Niño-Modoki (e.g., Ashok et al. 2007; Chen et al. 2014; Marathe et al. 2015; Wang et al. 2016; Xu and Guan 2017; Wang et al. 2018). During the consecutive years of 1983-85 and 1998-2001 when La Niña events occur, type-I precipitation is anomalously high, whereas during 1990-94 and 2002-06 when El Niño events occur, it is anomalously low (Fig. 3a). Meanwhile, the precipitation anomaly overall is negative on decadal time scales from 1987 to 2007. However, summer precipitation has been increasing since 2002. (Combined) anomalous precipitation pattern type II $+\mathrm{V}$ (Fig. 3b) displays a feature of strong interannual oscillation, with positive anomalies in 1990, 1992, 1998, 2010 and negative anomalies in 1991, 1994, and 1997, corresponding to strong positive and negative IOD years, suggesting that type-II $+\mathrm{V}$ precipitation is closely related to IOD. Precipitation of type II $+V$ generally shows a weak decreasing trend. An apparent change in type-III precipitation occurs around 2000 (Fig. 3c), showing mostly negative before 2000 but positive after 2000. (Combined) type-IV+VI precipitation displays large negative anomalies (Fig. 3d) in the early 1980s, with oscillations around the mean climatological value in the late 1980s and 1990s, exhibiting positive anomalies since the beginning of the twenty-first century. In general, all types of precipitation demonstrate large interannual variability, despite the significant differences among the time series of precipitation of these different types.

\section{b. Periodic features of precipitation variations}

Precipitation variations over different subregions of $\mathrm{MC}$ vary with different periodicities. It can be seen from Fig. 4a that anomalous precipitation significantly oscillates with periods of $2.5,4-6$, and quasi- $11 \mathrm{yr}$ in subregion I. However, the power spectrum of anomalous precipitation in subregion II $+\mathrm{V}$ (Fig. 4b) looks very different from that in the Indonesian region (Fig. 4a); the anomalous summer precipitation changes distinctly with periods of quasi- 3 years and 4-6 years. In the region near the equator in the western Pacific as indicated by subregion III, the precipitation anomaly exhibits 2-, 3.3-, and $7-10$-yr periods (Fig. $4 \mathrm{c}$ ), showing a very different feature from precipitation over subregion I (Fig. 4a), implying that this region is possibly less affected by ENSO. Again, these periods are quite different from those over subregion IV+VI where precipitation varies most significantly with periods of 2.5 years, quasi-5 years, and multidecades (Fig. 4d). The periods with 2-3 years of precipitation are found in all the 4 subregions, but the power spectra structures are distinctly different among these subregions. This result explains why the correlations between precipitation time series in different subregions are weak (Guan and Huang 1994). 

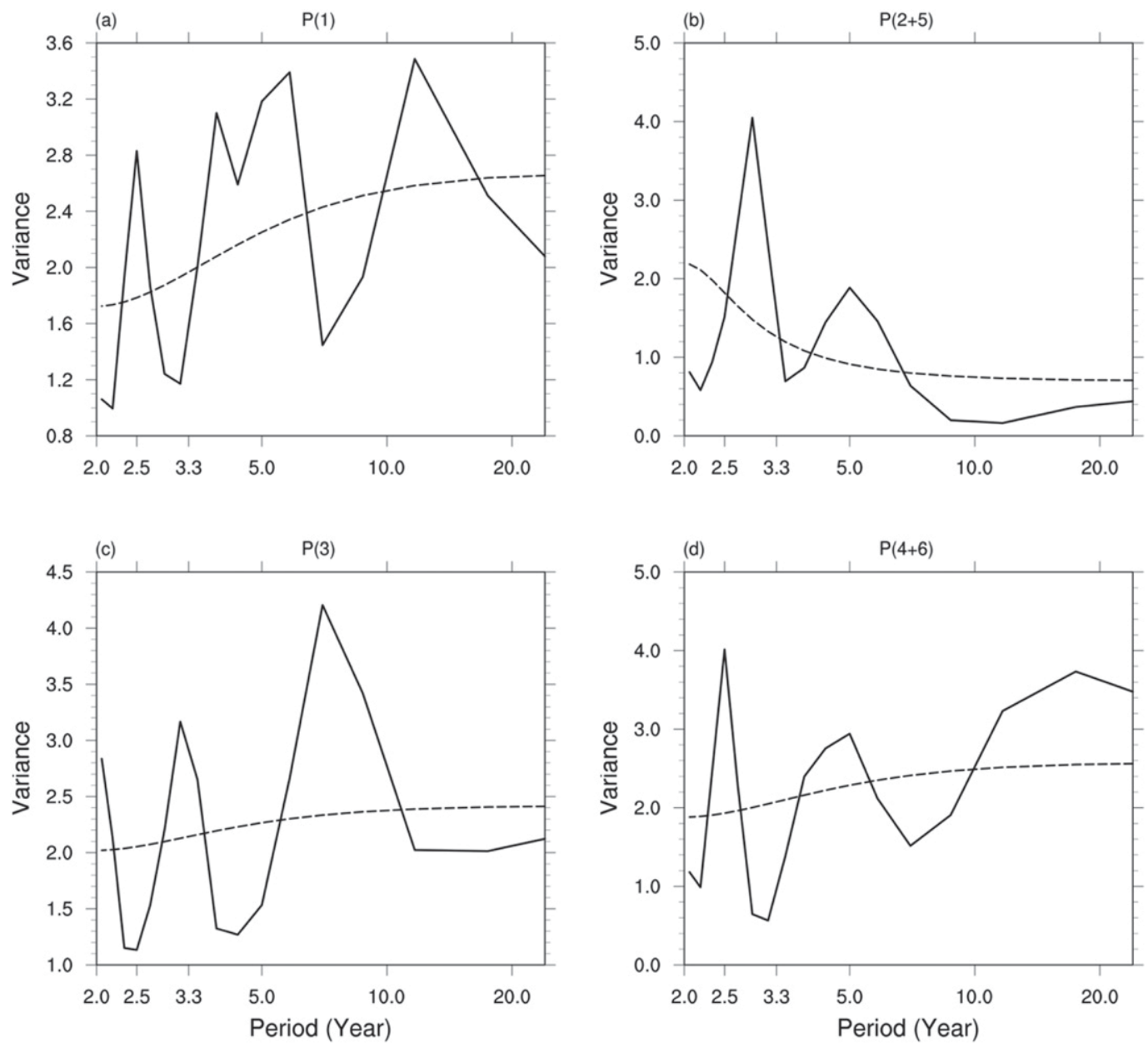

FIG. 4. Spectra of time series of summer precipitation (solid lines) for (a) type I, (b) type II+V, (c) type III, and (d) type IV+VI. The dashed lines indicate the $95 \%$ confidence level using red noise checking.

\section{c. Possible relations of precipitation with climate signals}

The power spectrum structures of precipitation time series in different subregions of MC as seen in Figs. 4a-d are very different. Reasons for such differences should be attributed to different signals related to both the anomalous atmospheric circulations and the anomalous forcings of sea surface temperature anomalies. Table 4 presents the correlations of time series of precipitation anomaly in each subregion with multiple indices (Table 5).

The anomalous precipitation in different subregions in the MC is found to be significantly correlated with different indices. In subregion I, the variations of anomalous precipitation are closely related to various ENSO indices including Niño-1+2, Niño-3, Niño-3.4, Southern Oscillation index (SOI), and El Niño Modoki index (EMI; Table 4). Particularly, the maximum correlation is found between precipitation anomalies in subregion I and Niño-3.4 index with a value of -0.83 , which can explain about $68.89 \%$ of the total variance of the anomalous precipitation in subregion I in the MC. These results suggest that the summer precipitation in the Indonesian region is strongly influenced by ENSO events, consistent with the results claimed in previous studies (e.g., Klein et al. 1999; Alexander et al. 2002; Lau and Nath 2003; Ashok et al. 2007; Nur'utami and Hidayat 2016; Xu and Guan 2017). Besides ENSO, the monsoon variations may also affect the type-I precipitation pattern; the anomalous precipitation is found to be significantly correlated with East Asian summer monsoon index (EASMI), Southeast Asian summer monsoon index (SEASMI), and South China Sea southern monsoon index (SCSSMI) with values of $-0.34,-0.39$, and -0.53 (Table 4). Precipitation variations in subregion II $+\mathrm{V}$ are highly correlated with central-Pacific type ENSO, IOD, and East Asian summer monsoon. The 
TABLE 4. Correlation coefficients of the time series of precipitation anomaly with multiple indices. The critical value at $95 \%$ confidence level is found to be 0.33 . Those coefficients with absolute values larger than 0.33 are denoted by an asterisk.

\begin{tabular}{lcrrr}
\hline \hline Indices & $P_{1}$ & $P_{2+5}$ & $P_{3}$ & $P_{4+6}$ \\
\hline Niño1+2 & $-0.36^{*}$ & -0.30 & -0.06 & $-0.40^{*}$ \\
Niño-3 & $-0.71^{*}$ & $-0.45^{*}$ & 0.13 & -0.15 \\
Niño-3.4 & $-0.83^{*}$ & $-0.50^{*}$ & 0.22 & 0.04 \\
EMI & $-0.58^{*}$ & -0.23 & $0.33^{*}$ & $0.35^{*}$ \\
DMI & -0.24 & $-0.84^{*}$ & 0.24 & -0.06 \\
SOI & $0.78^{*}$ & $0.56^{*}$ & -0.26 & 0.00 \\
EASMI & $-0.34^{*}$ & $-0.41^{*}$ & 0.27 & $0.49^{*}$ \\
SASMI & -0.10 & -0.25 & 0.18 & 0.18 \\
SEASMI & $-0.39^{*}$ & $-0.43^{*}$ & $0.48^{*}$ & $0.41^{*}$ \\
SWASMI & 0.04 & 0.03 & -0.02 & -0.03 \\
SCSSMI & $-0.53^{*}$ & $-0.59^{*}$ & $0.45^{*}$ & $0.36^{*}$ \\
PJ & -0.03 & 0.03 & -0.06 & $0.46^{*}$ \\
EAP & 0.11 & -0.27 & -0.09 & $0.33^{*}$ \\
\hline
\end{tabular}

strongest correlation coefficient is found between precipitation in subregion II $+\mathrm{V}$ and dipole mode index (DMI) with a value of -0.84 , which explains $70.56 \%$ of the total variance of precipitation anomalies, suggesting that the precipitation in subregion $\mathrm{II}+\mathrm{V}$ is possibly affected by IOD. Interestingly, no significant correlations are found between time series of summer precipitation anomalies averaged over subregion III and ENSO (IOD) indices in any one of the seasons including the past winter, the past spring, and the following autumn (Table 6). Moreover, no significant lead-lag (at most 5 years) correlations are found between summer precipitation over subregion III and summer indices of ENSO (IOD). Precipitation in subregion III is only weakly linked to El Niño Modoki (Ashok et al. 2007) with $10.89 \%$ of variance explained. Precipitation in subregion IV+VI is associated with eastern Pacific-type ENSO, El Niño Modoki, East Asian summer monsoon, and EAP/PJ teleconnection.

Of interest is that precipitation variations in all four subregions in the MC are found to be significantly correlated with SEASMI and SCSSMI. They are not significantly correlated with the South Asian summer monsoon index (SASMI) and southwest Asian summer monsoon index (SWASMI), however.

\section{The related circulation patterns}

\section{a. Water vapor transport}

The precipitation pattern for each subregion in the $\mathrm{MC}$ is characterized by its corresponding REOF mode (Fig. 1). However, it is not enough to explore those patterns in a larger tropical area. To examine the features of the precipitation patterns in more detail, we have calculated the correlations of time series of precipitation anomalies averaged over each of the four subregions with the anomalous precipitation and the related water vapor transports in a larger tropical area, which are presented in Fig. 5.

Type-I precipitation is highly positively correlated with tropical precipitation in KMC region (Fig. 5a), which is consistent with the result of REOF1 (Fig. 1) in the Maritime Continent. Meanwhile, large significant negative correlations are observed in region east of MC. The water vapor converges into subregion I not only from the equatorial western Pacific but also from the South China Sea, Indochina, the Bay of Bengal, and the tropical southeastern Indian Ocean (Fig. 5a), inducing more precipitation there. Note that the water vapor transport associated with precipitation anomaly in subregion I may possibly relate to the central-Pacific type ENSO (Xu and Guan 2017). Of course, from the water transport, it is expected that this anomalous precipitation pattern are influenced by the Southeast Asian, East Asian, and South China Sea summer monsoons (Table 4).

For type-II $+\mathrm{V}$ precipitation pattern (Fig. $5 b$ ), positive precipitation anomalies are mainly observed over the southeastern Indian Ocean where the southeastern pole of the Indian Ocean dipole is located (Saji et al. 1999). The water vapor supply for positive precipitation anomaly in this pattern largely comes from the equatorial Pacific and Indian Oceans (Fig. 5b). Both the cyclonic circulations of vapor fluxes above the Bay of Bengal and the southeastern Indian Ocean play an important role in transporting water vapor eastward over the equatorial Indian Ocean. From the anomalous circulation of water vapor fluxes, it is expected that this pattern is not only affected by ENSO and IOD but also by the South China Sea summer monsoon, Southeast Asian summer monsoon, and the East Asian summer monsoon, which are also examined in Table 4.

The precipitation pattern III (Fig. 5c) looks similar to the third REOF mode as seen in Fig. 1c in the MC region. Some positive correlations are also found in the equatorial Pacific east of the MC region. The water vapor converges into this subregion III from everywhere outside this subregion-not only from the Pacific but also from both the South China Sea and Indonesian archipelagos. Such a water vapor transport seems to be related to summer monsoon activities in Southeast Asia and the South China Sea, providing a favorable condition for positive precipitation anomaly in subregion III. Note that, as seen from the water vapor transports, this anomalous precipitation pattern occurs near the equatorial Pacific, which may be affected partly by both the South China Sea summer monsoon and Southeast Asian summer monsoon, consistent with the correlations in Table 4. In comparison with the type-I precipitation (Fig. 5a), however, this type-III precipitation pattern 
TABLE 5. Definitions of the indices employed in Table 4.

\begin{tabular}{|c|c|c|}
\hline Indices & Definition & Reference \\
\hline Niño-1+2 & Regional mean SSTA in $0^{\circ}-10^{\circ} \mathrm{S}, 90^{\circ}-80^{\circ} \mathrm{W}$ & NOAA Climate Prediction Center \\
\hline Niño-3 & Regional mean SSTA in $150^{\circ}-90^{\circ} \mathrm{W}, 5^{\circ} \mathrm{S}-5^{\circ} \mathrm{N}$ & NOAA Climate Prediction Center \\
\hline Niño-3.4 & Regional mean SSTA in $170^{\circ}-120^{\circ} \mathrm{W}, 5^{\circ} \mathrm{S}-5^{\circ} \mathrm{N}$ & NOAA Climate Prediction Center \\
\hline EMI & $\begin{array}{l}\text { SSTA }_{\text {BOX-A }}-\left(0.5 \times \text { SSTA }_{\text {BOX-B }}\right)-(0.5 \times \\
\left.\text { SSTA }_{\text {BOX-C }}\right) \text {, in which the three terms on } \\
\text { the right-hand side of the equation are } \\
\text { derived from the area-averaged SSTA over } \\
\text { each of the regions A }\left(165^{\circ} \mathrm{E}-140^{\circ} \mathrm{W}, 10^{\circ} \mathrm{S}-\right. \\
\left.10^{\circ} \mathrm{N}\right), \mathrm{B}\left(110^{\circ}-70^{\circ} \mathrm{W}, 15^{\circ}-5^{\circ} \mathrm{N}\right) \text {, and } \mathrm{C} \\
\left(125^{\circ}-145^{\circ} \mathrm{E}, 10^{\circ} \mathrm{S}-20^{\circ} \mathrm{N}\right) \text {, respectively }\end{array}$ & Ashok et al. (2007) \\
\hline DMI & $\begin{array}{l}\text { Anomalous SST gradient between the western } \\
\text { equatorial Indian Ocean }\left(50^{\circ}-70^{\circ} \mathrm{E}, 10^{\circ} \mathrm{S}-\right. \\
\left.10^{\circ} \mathrm{N}\right) \text { and the southeastern equatorial In- } \\
\text { dian Ocean }\left(90^{\circ}-110^{\circ} \mathrm{E}, 10^{\circ} \mathrm{S}-0^{\circ} \mathrm{N}\right)\end{array}$ & Saji et al. (1999) \\
\hline SOI & $\begin{array}{l}\text { Standardized time series of the sea level } \\
\text { pressure difference between Tahiti and } \\
\text { Darwin Islands }\end{array}$ & NOAA Climate Prediction Center \\
\hline EASMI & $\begin{array}{l}\text { Regional mean anomalous sea surface wind in } \\
10^{\circ}-40^{\circ} \mathrm{N}, 110^{\circ}-140^{\circ} \mathrm{E} \text { at } 850 \mathrm{hPa}\end{array}$ & Li and Zeng $(2002,2003,2005)$ \\
\hline SASMI & $\begin{array}{l}\text { Wind at } 850 \mathrm{hPa} \text { averaged over the region } \\
5^{\circ}-22.5^{\circ} \mathrm{N}, 35^{\circ}-97.5^{\circ} \mathrm{E}\end{array}$ & Li and Zeng $(2002,2003,2005)$ \\
\hline SEASMI & $\begin{array}{l}\text { Wind at } 850 \mathrm{hPa} \text { averaged over the region } \\
2.5^{\circ}-20^{\circ} \mathrm{N}, 70^{\circ}-110^{\circ} \mathrm{E}\end{array}$ & Li and Zeng $(2002,2003,2005)$ \\
\hline SWASMI & $\begin{array}{l}\text { Wind at } 850 \mathrm{hPa} \text { averaged over the region } \\
2.5^{\circ}-20^{\circ} \mathrm{N}, 35^{\circ}-70^{\circ} \mathrm{E}\end{array}$ & Li and Zeng (2002) \\
\hline SCSSMI & $\begin{array}{l}\text { Wind at } 850 \mathrm{hPa} \text { averaged over the region } \\
0^{\circ}-25^{\circ} \mathrm{N}, 100^{\circ}-125^{\circ} \mathrm{E}\end{array}$ & Li and Zeng (2002) \\
\hline PJ & $\begin{array}{l}\text { Geopotential height gradient between } 155^{\circ} \mathrm{E} \text {, } \\
35^{\circ} \mathrm{N} \text { and } 125^{\circ} \mathrm{E}, 22.5^{\circ} \mathrm{N} \text { at } 850 \mathrm{hPa}\end{array}$ & $\begin{array}{l}\text { Nitta (1987), Wakabayashi and } \\
\text { Kawamura (2004) }\end{array}$ \\
\hline EAP & $\begin{array}{l}I_{\mathrm{A}}-0.5 I_{\mathrm{B}}-0.5 I_{\mathrm{C}} \text {, in which the three terms on } \\
\text { the right-hand side of the equation are } \\
\text { derived from the standardized time series of } \\
\text { geopotential height at } 500 \mathrm{hPa} \text { at each of the } \\
\text { points } \mathrm{A}\left(125^{\circ} \mathrm{E}, 40^{\circ} \mathrm{N}\right), \mathrm{B}\left(125^{\circ} \mathrm{E}, 60^{\circ} \mathrm{N}\right), \\
\text { and } \mathrm{C}\left(125^{\circ} \mathrm{E}, 20^{\circ} \mathrm{N}\right) \text {, respectively }\end{array}$ & Huang and Li (1987), Huang (2004) \\
\hline
\end{tabular}

may be less affected by ENSO because no evident anomalous easterly equatorial flow is observed east of the convergence center (Fig. 5c).

The type-IV + VI pattern of anomalous precipitation (Fig. 5d) looks similar to type III except for the shifted location. The positive correlation center is observed in tropical northwestern Pacific off equator. The water

TABLE 6. Correlations of summer rainfall anomalies over subregion III with the ENSO indices of different seasons. The critical correlation values at $90 \%$ and $95 \%$ confidence levels are found to be 0.28 and 0.33 , respectively, using a $t$ test when the number of degrees of freedom is 33 .

\begin{tabular}{lccr}
\hline \hline \multicolumn{1}{c}{ Seasons } & Niño-1+2 & Niño-3.4 & IOD \\
\hline Past winter & -0.14 & -0.25 & -0.30 \\
Past spring & -0.12 & -0.11 & 0.10 \\
Summer & -0.06 & 0.22 & 0.24 \\
Following autumn & -0.13 & 0.16 & 0.23 \\
Following winter & -0.14 & 0.04 & 0.04 \\
\hline
\end{tabular}

vapor significantly converges into subregion IV+VI from both the northern and western sides of this region. No significant divergent components of water vapor fluxes are observed in the area south of this subregion. The anomalous transport of water vapor in association with this type-IV+VI pattern may be influenced by the central Pacific (CP)-type ENSO (Ashok et al. 2007; Kug et al. 2009; Weng et al. 2009; Wang et al. 2018). Apart from the SSTA influences, the anomalous precipitation may also be related to the anomalous East Asian summer monsoon and EAP/PJ teleconnection pattern (Huang and Li 1987; Nitta 1987), as indicated in Table 4.

\section{b. Circulation anomalies}

The regional anomalous precipitation over different subregions is induced by different anomalous circulation patterns. This situation can be explored further in the regression of circulation anomalies during 1979-2013 on 

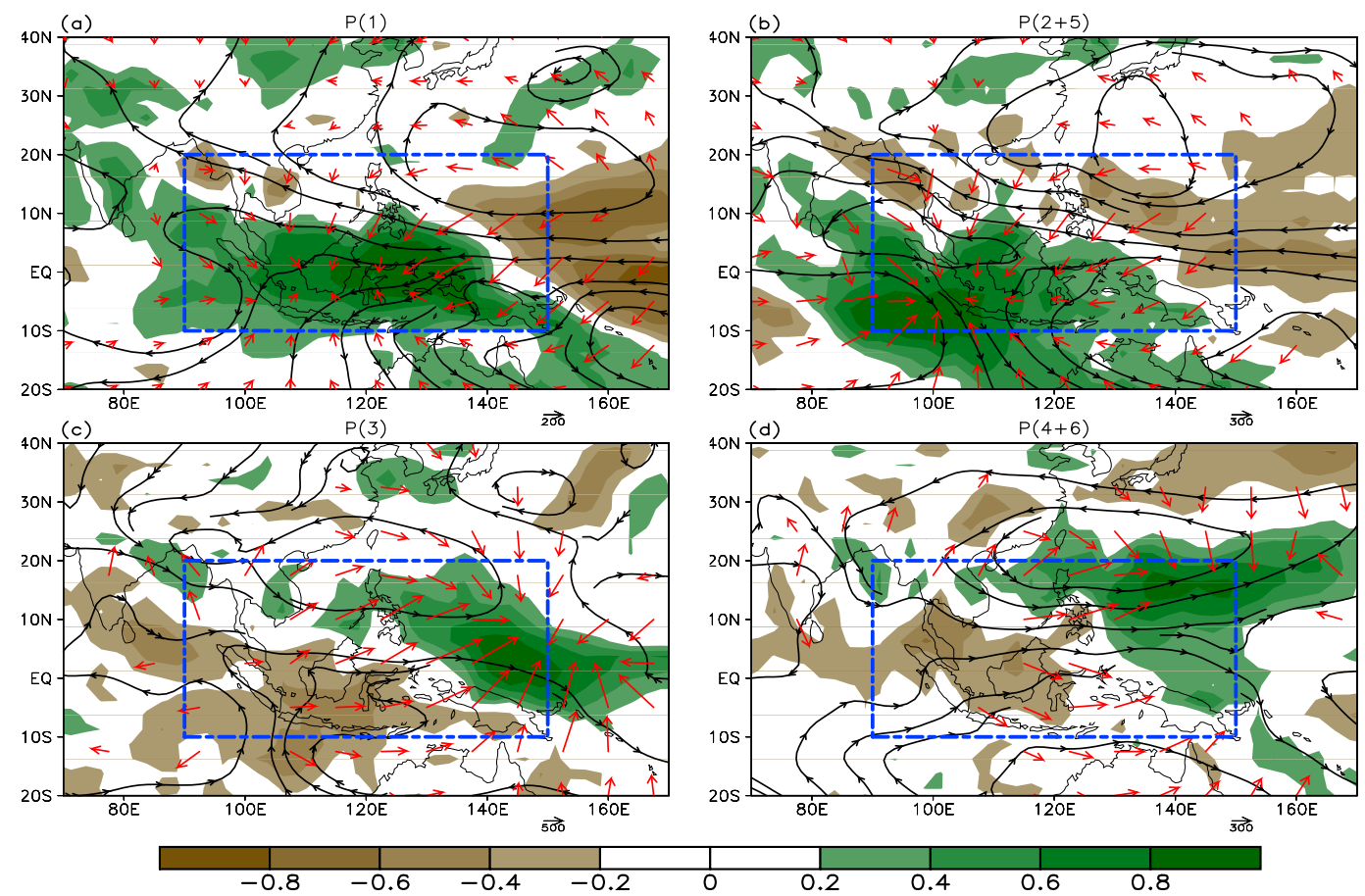

FIG. 5. Correlations (shaded) of precipitation during 1979-2013 with that in (a) subregion I, (b) subregion II +V, (c) subregion III, and (d) subregion IV+VI. Regression coefficients of divergent and rotational components of abnormal water vapor flux integrated vertically from the surface up to $300 \mathrm{hPa}$ are displayed with arrows (above $95 \%$ level of confidence) and streamlines, respectively. These regression coefficients are obtained by regressing these components of vapor fluxes onto the normalized time series of summer anomalous precipitation in each subregion in the MC.

time series of precipitation anomalies in each subregion (Fig. 6). The WAF are also presented using the approach proposed by Takaya and Nakamura (2001).

The anomalous circulation related to the type-I precipitation pattern indicates that significant easterly wind anomalies at $850 \mathrm{hPa}$ prevail over the $\mathrm{MC}$ and the equatorial area to its east when precipitation is abnormally high in subregion I (Fig. 6a) while an anomalous cyclonic circulation exists over Sumatra, inducing the anomalous convergence over the equator in the lower troposphere. At $200 \mathrm{hPa}$ (Fig. 6b), anomalous divergence as shown by anomalous velocity potential occurs over subregion I, which is favorable for ascending motion there. The distribution of wave activity fluxes at $850 \mathrm{hPa}$ suggests that the disturbance over the MC may affect the circulation in regions northeast of the MC, resulting in strengthening of the anomalous anticyclonic circulation over the southern part of China and the northwestern Pacific. Note that a weak cyclonic circulation appears over the ocean to the east of Japan, and the divergence to the east of the Philippines might trigger Rossby waves and form the weak EAP/PJ teleconnection pattern (Huang and Li 1987; Nitta 1987). However, because this teleconnection looks very weak and its location shifts eastward, the correlation coefficient of anomalous precipitation over subregion I with the PJ/EAP index is not significant (Table 4).

Precipitation anomalies in subregion II $+\mathrm{V}$ are influenced by perturbations over the equatorial oceans, especially by those over the equatorial Indian Ocean. At $850 \mathrm{hPa}$ (Fig. 6c), anomalous southeasterly flows appear in northern MC while anomalous northwesterly flows appear in southwestern MC. An anomalous convergence center is observed over subregion $\mathrm{II}+\mathrm{V}$ in the lower troposphere, where the positive anomalous precipitation is induced. A pair of anomalous cyclonic circulations on both sides of equator appears to the west of this anomalous convergence center, which is explained as the Gill-type response of atmosphere to the anomalous thermal forcing due to the convections over the subregion II +V (Gill 1980). The Philippines, China, and the oceanic area to the east of Japan are under the control of an anomalous anticyclonic circulation, which combines with the anomalous cyclonic circulation in western MC to form a teleconnection pattern similar to EAP/PJ. The WAF indicates that some wave energy propagates northeastward from MC region (Fig. 6c). This result is consistent with that of Guan and Yamagata 

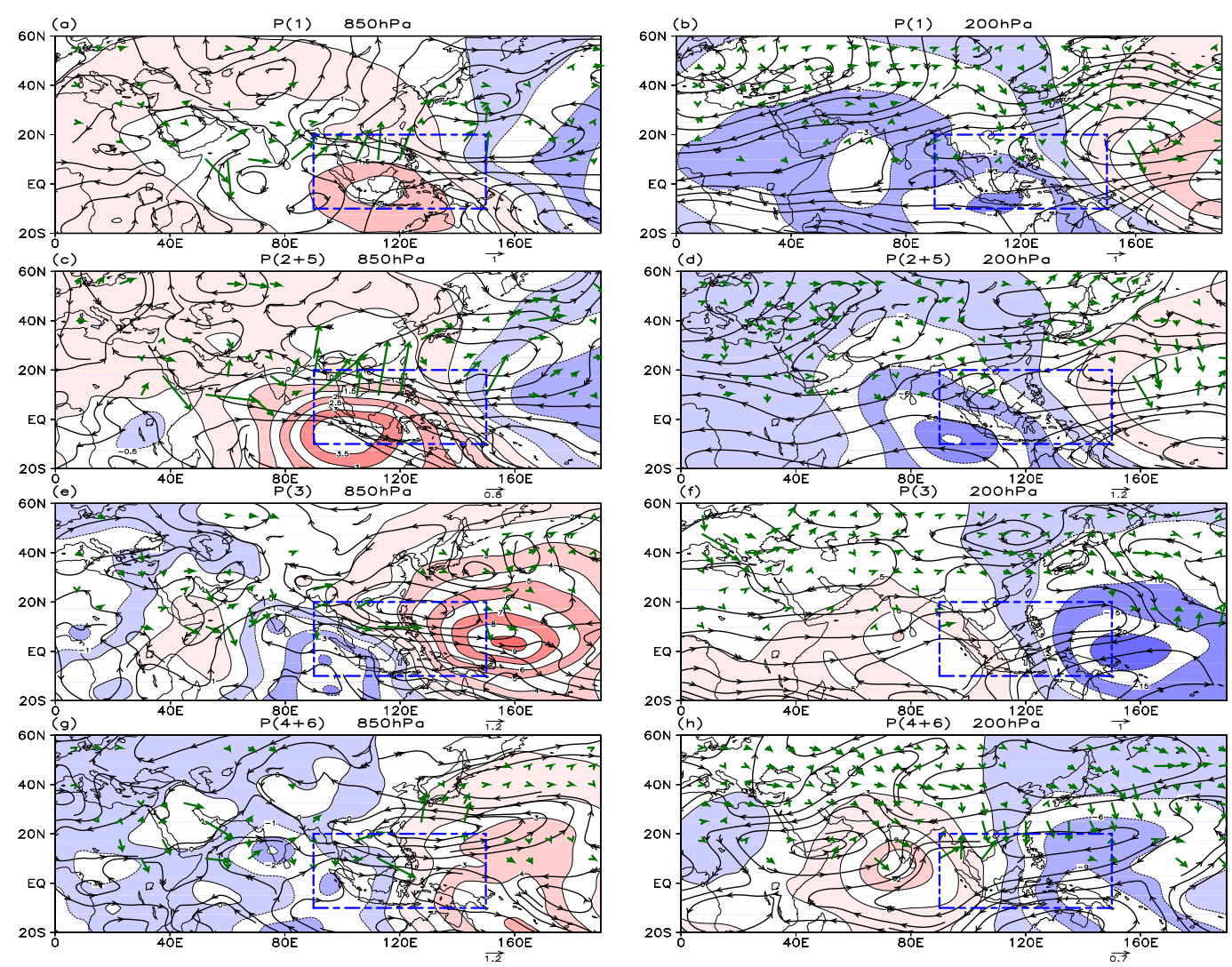

FIG. 6. Regressed circulation anomalies during 1979-2013 as obtained by regressing physical quantities upon time series of anomalous precipitation in subregions (a),(b) I; (c),(d) II + V; (e),(f) III; and (g),(h) IV + VI for (left) 850 and (right) $200 \mathrm{hPa}$. Arrows (green) with values larger than $3 \mathrm{~m}^{2} \mathrm{~s}^{-2}$ are shown for Takaya and Nakamura (2001) wave activity fluxes. Streamlines are for the rotational components of anomalous winds, whereas the streaked shaded areas are for anomalous velocity potential, which is defined as the greater value (smaller value) centers for convergence (divergence).

(2003) in their study of the IOD effects in 1994. At $200 \mathrm{hPa}$ (Fig. 6d), anomalous circulations look opposite to those in the lower troposphere as seen in Fig. 6c.

Corresponding to higher-than-normal precipitation in subregion III, an anomalous convergence center is found at $850 \mathrm{hPa}$ over the region near the east border of the MC (Fig. 6e), which excites two zonal-extending narrow anomalous cyclonic circulations on both sides of the equator in the $\mathrm{MC}$ region. Because of these two anomalous cyclonic circulations, one observes the anomalous westerly winds blowing into subregion III, facilitating the anomalous convergence there. Note that the anomalous convergence center may be induced by the anomalous warming due to the positive SST anomalies in subregion III. The vertical structure of the abnormal circulation displays baroclinic features in the tropical region as expected (Figs. 6e,f). Note that no obvious anomalous equatorial zonal air flows are observed east of $160^{\circ} \mathrm{E}$ (Figs. 6e,f), suggesting that ENSO may have little impact on the rainfall anomalies in subregion III.
Similarly, when a positive precipitation anomaly appears in subregion IV+VI, at $850 \mathrm{hPa}$, a pair of anomalous cyclonic circulations appears to the north and south of the equator (Fig. $6 \mathrm{~g}$ ). The southeastern flank of the one to the north of the equator covers subregion IV+VI. The convergence centered at $\left(15^{\circ} \mathrm{N}, 170^{\circ} \mathrm{E}\right)$ as a positive vorticity source triggers and maintains the anomalous cyclonic circulation in the northwestern Pacific. This anomalous cyclonic circulation induces EAP/PJ-type wave trains that propagate northeastward in the lower troposphere (Kosaka and Nakamura 2006), affecting the summer climate in East Asia. The WAF in Fig. $6 \mathrm{~g}$ also suggests that this EAP/PJ teleconnection is excited. This result is consistent with the significant correlations of precipitation anomalies with both the indices of EAP and PJ patterns.

\section{c. SST anomalies}

The different patterns of anomalous precipitation in the MC must be induced by different patterns of SSTA 

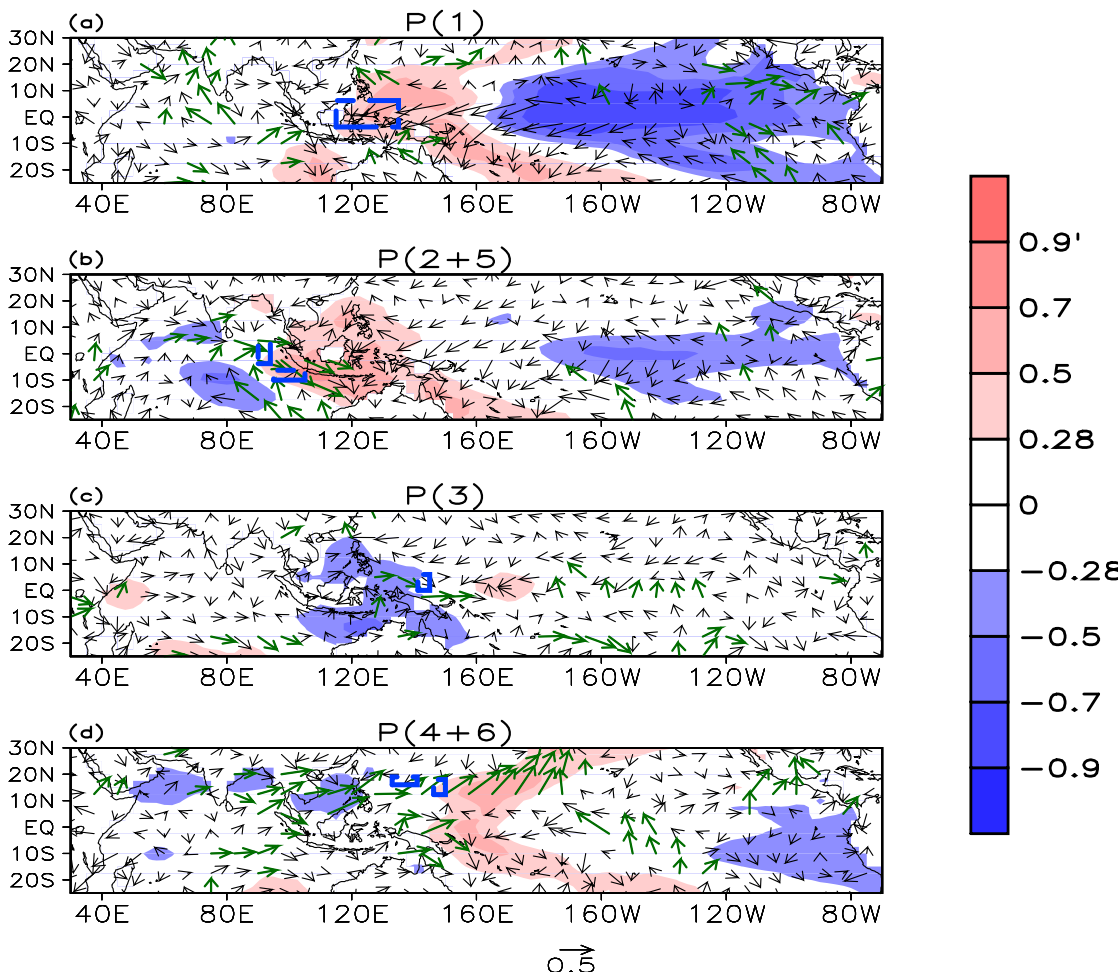

FIG. 7. Correlation coefficients (shaded) of precipitation time series in (a) subregion I, (b) subregion II + V, (c) subregion III, and (d) subregion IV+VI with SSTA. Arrows indicate the vectors composed of the correlation coefficients of anomalous precipitation series with anomalous zonal surface wind as the zonal component and with the anomalous meridional surface winds as the meridional component of the vectors. Shaded areas and thick arrows are for values at or above the $90 \%$ confidence level.

forcing. To explore this possibility, we present in Fig. 7 the correlation coefficients of SST anomalies with precipitation time series in the four subregions.

The anomalous precipitation in subregion I is positively correlated with SSTAs in the warm-pool region of western Pacific and the South Pacific convergence zone (SPCZ) region but negatively correlated with SSTA in the equatorial central and eastern Pacific (Fig. 7a). This indicates that the type-I precipitation variability is only closely associated with typical CP-type SSTA events, being dominated by CP-type ENSO during boreal summer (e.g., Wang et al. 2018). It is interesting that this anomalous precipitation pattern seems to have nothing to do with the SSTA forcing from the tropical Indian Ocean.

However, the situation changes for precipitation variations in subregion II + V. It can be seen from Fig. 7b that significant positive correlations appear in the MC, while negative correlations appear in the eastern equatorial Pacific and in the central-western part of the tropical Indian Ocean, exhibiting a triple structure of SSTAs in the Indo-Pacific sector. This suggests that both El Niño and the IOD may affect the precipitation anomalies in subregion II $+\mathrm{V}$. In fact, the larger positive correlations are observed near Sumatra along with the negative correlations in central-western parts of the tropical region, exhibiting the zonal anomalous SSTA gradient like the Indian Ocean dipole (Saji et al. 1999), suggesting the anomalous precipitation in subregion $\mathrm{II}+\mathrm{V}$ is significantly correlated with the DMI as listed in Table 4. On the other hand, the precipitation variations are also significantly correlated with Niño indices (Table 4) although the correlations are not so strong when compared with the type-I precipitation pattern.

The SSTA related to the type-III precipitation pattern demonstrates that the significant correlations are mainly confined in the tropical west Pacific. This is a regional thermal forcing-driven pattern with thermal forcing contrast between the MC and the small region in east flank of the MC. It seems that it has nothing to do with the canonical El Niño signal except that El Niño Modoki may have limited impacts on this precipitation pattern besides tropical monsoon influences (Table 4). Moreover, note again that subregion III is really a strange place where the relationship between rainfall variations and ENSO is a puzzle. To simply explore this relationship, the lead-lag correlations of time series of 
anomalous summer rainfall averaged over subregion III with the ENSO indices in different seasons are presented in Table 6. Both the lead and lag correlations demonstrate that the rainfall variation over subregion III has almost nothing to do with ENSO; the correlations are not significant at all at the $95 \%$ confidence level for effective degrees of freedom ranging from 28 to 33 . This seems to deserve deep investigation in the future.

The anomalous precipitation in region IV+VI is significantly and positively correlated with the SSTAs in the Pacific domain, with a " $<$ "-like narrow belt that stretches northeastward and southeastward from the equatorial region near $160^{\circ} \mathrm{E}$. This SSTA pattern looks very special. It may have something to do with the El Niño Modoki, as suggested in Table 4. At the same time, the negative weak correlations are found in Niño- $1+2$ regions, exhibiting again the significant correlation between the type-IV+VI precipitation pattern and Niño$1+2$, index as seen in Table 4. Interestingly, when significant colder SSTAs co-occur in the Arabian Sea, the Bay of Bengal, and the South China Sea, the precipitation in subregion IV+VI will be significantly greater than normal. Of course, as suggested in Table 4, this type of precipitation anomaly is closely related to the East Asian summer monsoon.

\section{Conclusions}

The precipitation variations in the Maritime Continent region have been investigated above. Conclusions are made as follows.

In the Northern Hemisphere summer (June-September), there exist large differences in the spatial and temporal distribution of precipitation over the MC. Based on REOF analysis, the MC can be divided into four key subregions for precipitation: subregion $\mathrm{I}$ in centraleastern Indonesia, subregion II $+\mathrm{V}$ in the oceanic area to the west of Indonesia, subregion III in the warm-pool region in the equatorial western Pacific, and subregion IV+VI around Guam. Time series of each type of precipitation pattern display significant interannual variability, but precipitation variations in these four different subregions are statistically independent of each other.

Different anomalous precipitation patterns are induced by water vapor converging from different regions. For positive precipitation anomalies in subregion I, the water vapor supply largely comes from the equatorial Pacific, whereas for subregion II $+\mathrm{V}$, it comes from both the equatorial Pacific and the Indian Ocean. A positive precipitation anomaly in subregion III is attributed to the converging of water vapor transported westward from the tropical Pacific and eastward from both the South China Sea and Indonesia. In subregion IV+VI, the water vapor supply for positive precipitation anomalies is mainly from the Bay of Bengal, the South China Sea, and the Pacific Ocean to the east of the Philippines.

The anomalous atmospheric circulation patterns as responses to the different SSTA patterns are responsible for explaining the formation of the different precipitation anomaly patterns in different subregions. When the precipitation anomaly is positive in subregion I, an anticlockwise circulation appears at $850 \mathrm{hPa}$ over Indonesia and Malaysia that is accompanied by significant convergence and ascending motion above the equatorial MC region. Meanwhile, positive SST anomalies exist in the warm pool of the western Pacific and the SPCZ region with negative SST anomalies in the central-eastern $\mathrm{Pa}$ cific. There is almost no significant SSTA in tropical Indian Ocean. These suggest that the precipitation in subregion I is induced by tropical Pacific signals such as the CP type of ENSO events rather than signals from tropical Indian Ocean. However, when a positive precipitation anomaly occurs in subregion II $+\mathrm{V}$, the anomalous cyclonic circulations appear in the lower troposphere at both sides of the equator to the west of MC. This circulation pattern is formed as a response to the triple pattern of SSTA with a positive SSTA center in the MC along with negative centers in the western-central tropical Indian Ocean and equatorial central-eastern Pacific. These indicate that both the ENSO and IOD events possibly affect the precipitation variations in subregion II $+\mathrm{V}$. When precipitation is abnormally high in subregion III, a pair of anomalous cyclonic circulations at $850 \mathrm{hPa}$ that are roughly symmetric about equator occupy the eastern part of MC as a Gill-type response of atmosphere to the anomalous warm SSTA center near subregion III. This type-III pattern of precipitation anomalies mainly resulted from the thermal forcing of the SSTA pattern with cooling in the eastern part of the MC and warming at the equator outside but near the east border of the MC. It should be emphasized that this typeIII precipitation pattern is found to be statistically independent of ENSO and IOD, although subregion III is over the equator in the eastern part of the MC. This independence of variations of type-III rainfall to both ENSO and IOD is roughly explained by the atmospheric response to the anomalous thermal forcings of local interannual variability of SSTAs rather than the remote forcing of ENSO and IOD. A positive precipitation anomaly occurs in subregion IV+VI when this region is under the influence of the southeastern flank of the abnormal cyclonic circulation in the lower troposphere to the north of the equator. This abnormal cyclonic circulation can trigger a northeastward-propagating EAP/PJ wave train. No significant SST anomalies are found in this subregion, but a positive SST anomaly appears in 
the tropical northwestern Pacific with a $<$-like, or horseshoe-like, pattern while a negative SST anomaly appears in the Arabian Sea, the Bay of Bengal, and especially in the South China Sea. Besides the SSTAinduced thermal forcing, it is noticed that the variations of East Asian and SCS summer monsoon circulations also play significant roles in inducing the anomalous precipitation in these four subregions.

Note that from the data analysis we find that the different circulation patterns in association with the abovementioned four anomalous precipitation patterns in the MC are largely induced by the different SSTA patterns in the tropical Indo-Pacific sector as a result of responses of the atmosphere to the anomalous thermal forcings. However, there are still some questions to be answered in the future. For example, the precipitation over subregion III is somewhat independent of tropical climate variations such as ENSO and IOD. It seems that the variability of precipitation in subregion III deserves further deep investigation. It seems that there are some (inter)decadal changes, including the possible long-term trends in precipitation variations in subregion IV+VI (Fig. 3d); the correlation of the time series of precipitation over subregion IV+VI and Pacific decadal oscillation (PDO) is 0.31 , although weak. Whether there are some relationships between precipitation in subregion IV+VI and PDO needs further investigation. More than these, the six precipitation patterns are derived from the GPCP rainfall data. It would also be interesting to examine whether these patterns change much when different reanalysis data are used. Some sensitivity experiments using a proper AGCM are also needed to further examine whether the SSTAs play a crucial role in formation of these six precipitation patterns. These deserve future investigation.

Acknowledgments. This work is jointly supported by the project of Natural Science Foundation of China (41330425), and the PAPD project of Jiangsu Province. Data services are provided by Nanjing Atmospheric Information Center of Department of Earth Science (Nanjing University of Information Science and Technology); NCEP-NCAR reanalyses are downloaded from the NOAA Earth System Research Laboratory (http://www.esrl.noaa.gov/). Figures are plotted using the Grads and NCL software packages.

\section{REFERENCES}

Adler, R. F., and Coauthors, 2003: The Version-2 Global Precipitation Climatology Project (GPCP) monthly precipitation analysis (1979-present). J. Hydrometeor., 4, 1147-1167, https:// doi.org/10.1175/1525-7541(2003)004<1147:TVGPCP >2.0.CO;2.
Alexander, M. A., I. Bladé, M. Newman, J. R. Lanzante, N. Lau, and J. D. Scott, 2002: The atmospheric bridge: The influence of ENSO teleconnections on air-sea interaction over the global oceans. J. Climate, 15, 2205-2231, https://doi.org/10.1175/15200442(2002)015<2205:TABTIO > 2.0.CO;2.

Ashok, K., Z. Guan, N. H. Saji, and T. Yamagata, 2004: Individual and combined influences of ENSO and the Indian Ocean dipole on the Indian summer monsoon. J. Climate, 17, 3141-3155, https:// doi.org/10.1175/1520-0442(2004)017<3141:IACIOE>2.0.CO;2.

_ S. K. Behera, S. A. Rao, H. Weng, and T. Yamagata, 2007: El Niño Modoki and its teleconnection. J. Geophys. Res., 112, C11007, https://doi.org/10.1029/2006JC003798.

Chen, W., and Z. Guan, 2017: A joint monsoon index for East Asian-Australian monsoons during boreal summer. Atmos. Sci. Lett., 18, 403-408, https://doi.org/10.1002/asl.782.

Chen, Z., Z. Wen, R. Wu, P. Zhao, and J. Cao, 2014: Influence of two types of El Niños on the East Asian climate during boreal summer: A numerical study. Climate Dyn., 43, 469-481, https://doi.org/10.1007/s00382-013-1943-1.

Dayem, K. E., D. C. Noone, and P. Molnar, 2007: Tropical western Pacific warm pool and Maritime Continent precipitation rates and their contrasting relationships with the Walker circulation. J. Geophys. Res., 112, 151-156, https://doi.org/10.1029/ 2006JD007870.

Gill, A. E., 1980: Some simple solutions for heat-induced tropical circulation. Quart. J. Roy. Meteor. Soc., 106, 447-462, https:// doi.org/10.1002/qj.49710644905.

Guan, Z., and S. Huang, 1994: Atmospheric wave and its physical essence as revealed by changed correlation coefficients and correlation field. Acta Meteor. Sin., 8, 178-186.

, and T. Yamagata, 2003: The unusual summer of 1994 in East Asia: IOD teleconnections. Geophys. Res. Lett., 30, 1544, https://doi.org/10.1029/2002GL016831.

Horel, J. D., 1981: A rotated principal component analysis of the interannual variability of the Northern Hemisphere $500 \mathrm{mb}$ height field. Mon. Wea. Rev., 109, 2080-2092, https://doi.org/ 10.1175/1520-0493(1981)109<2080:ARPCAO>2.0.CO;2.

Huang, G., 2004: An index measuring the interannual variation of the East Asian summer monsoon-The EAP index. $A d v$. Atmos. Sci., 21, 41-52, https://doi.org/10.1007/BF02915679.

Huang, R., and W. Li, 1987: Influence of heat source anomaly over the tropical western Pacific on the subtropical high over East Asia. Proc. Int. Conf. on the General Circulation of East Asia, Chengdu, China, Chinese Academy of Sciences, 40-45.

Jin, D., Z. Guan, and W. Tang, 2013: The extreme drought event during winter-spring of 2011 in East China: Combined influences of teleconnection in midhigh latitudes and thermal forcing in Maritime Continent region. J. Climate, 26, 82108222, https://doi.org/10.1175/JCLI-D-12-00652.1.

,-- J. Cai, and W. Tang, 2015: Interannual variations of regional summer precipitation in mainland China and their possible relationships with different teleconnections in the past five decades. J. Meteor. Soc. Japan, 93, 265-283, https:// doi.org/10.2151/jmsj.2015-015.

—- H. Saji, and L. Huo, 2016: Recent changes in ENSO teleconnection over the western Pacific impacts the eastern China precipitation dipole. J. Climate, 29, 7587-7598, https://doi.org/ 10.1175/JCLI-D-16-0235.1.

Kanamitsu, M., W. Ebisuzaki, J. Woollen, S.-K. Yang, J. J. Hnilo, M. Fiorino, and G. L. Potter, 2002: NCEP-DOE AMIP-II reanalysis (R-2). Bull. Amer. Meteor. Soc., 83, 1631-1643, https://doi.org/10.1175/BAMS-83-11-1631. 
Kim, B. H., and K. J. Ha, 2015: Observed changes of global and western Pacific precipitation associated with global warming SST mode and mega-ENSO SST mode. Climate Dyn., 45, 3067-3075, https://doi.org/10.1007/s00382-015-2524-2.

Klein, S. A., B. J. Soden, and N. Lau, 1999: Remote sea surface temperature variations during ENSO: Evidence for a tropical atmospheric bridge. J. Climate, 12, 917-932, https://doi.org/ 10.1175/1520-0442(1999)012<0917:RSSTVD>2.0.CO;2.

Kosaka, Y., and H. Nakamura, 2006: Structure and dynamics of the summertime Pacific-Japan teleconnection pattern. Quart. J. Roy. Meteor. Soc., 132, 2009-2030, https://doi.org/10.1256/qj.05.204.

Kug, J. S., F. Jin, and S. An, 2009: Two types of El Niño events: Cold tongue El Niño and warm pool El Niño. J. Climate, 22, 1499-1515, https://doi.org/10.1175/2008JCLI2624.1.

Lau, N., and M. J. Nath, 2003: Atmosphere-ocean variations in the Indo-Pacific sector during ENSO episodes. J. Climate, 16, 3-20, https://doi.org/10.1175/1520-0442(2003) 016<0003:AOVITI>2.0.CO;2.

Li, J., and Q. Zeng, 2002: A unified monsoon index. Geophys. Res. Lett., 29, 1274, https://doi.org/10.1029/2001GL013874.

_, and - 2003: A new monsoon index and the geographical distribution of the global monsoons. Adv. Atmos. Sci., 20, 299302, https://doi.org/10.1007/BF02690792.

$\longrightarrow$, and - 2005: A new monsoon index, its interannual variability and relation with monsoon precipitation (in Chinese). Climatic Environ. Res., 10, 351-365.

Li, T., 2014: Recent advance in understanding the dynamics of the Madden-Julian oscillation. J. Meteor. Res., 28, 1-33, https:// doi.org/10.1007/s13351-014-3087-6.

Liu, Y., Z. Chen, and G. Wu, 2003: Impacts of the onset of the Bay of Bengal monsoon on the onset of the South China Sea monsoon. Part II: Numerical experiments (in Chinese). Acta Meteor. Sin., 61, 10-19.

Madden, R. A., and P. R. Julian, 1972: Description of global-scale circulation cells in the tropics with a 40-50 day period. J. Atmos. Sci., 29, 1109-1123, https://doi.org/10.1175/15200469(1972)029<1109:DOGSCC > 2.0.CO;2.

Marathe, S., K. Ashok, P. Swapna, and T. P. Sabin, 2015: Revisiting El Niño Modokis. Climate Dyn., 45, 3527-3545, https://doi.org/ 10.1007/s00382-015-2555-8.

McBride, J. L., M. R. Haylock, and N. Nicholls, 2003: Relationships between the Maritime Continent heat source and the El Niño-Southern Oscillation phenomenon. J. Climate, 16, 2905-2914, https://oi.org/10.1175/ 1520-0442(2003)016<2905:RBTMCH >2.0.CO;2.

Mori, S., and Coauthors, 2004: Diurnal land-sea rainfall peak migration over Sumatra island, Indonesian Maritime Continent observed by TRMM satellite and intensive rawinsonde soundings. Mon. Wea. Rev., 132, 2021-2039, https://doi.org/ 10.1175/1520-0493(2004)132<2021:DLRPMO >2.0.CO;2.

Neale, R., and J. Slingo, 2003: The Maritime Continent and its role in the global climate: A GCM study. J. Climate, 16, 834-848, https:// doi.org/10.1175/1520-0442(2003)016<0834:TMCAIR >2.0.CO;2.

Nitta, T., 1987: Convective activities in the tropical western Pacific and their impact on the Northern Hemisphere summer circulation. J. Meteor. Soc. Japan, 64, 373-390, https://doi.org/ 10.2151/jmsj1965.64.3_373.

Nur'utami, M., and R. Hidayat, 2016: Influences of IOD and ENSO to Indonesian rainfall variability: Role of atmosphere-ocean interaction in the Indo-Pacific sector. Procedia Environ. Sci., 33, 196-203, https://doi.org/10.1016/j.proenv.2016.03.070.

Qian, J. H., 2008: Why precipitation is mostly concentrated over islands in the Maritime Continent. J. Atmos. Sci., 65, 14281441, https://doi.org/10.1175/2007JAS2422.1.
Ramage, C. S., 1968: Role of a tropical "Maritime Continent" in the atmospheric circulation. Mon. Wea. Rev., 96, 196199, https://doi.org/10.1175/1520-0493(1968)096<0365: ROATMC $>2.0 . \mathrm{CO} ; 2$

Richman, M. B., 1981: Obliquely rotated principal components: An improved meteorological map typing technique. J. Appl. Meteor., 20, 1145-1159, https://doi.org/10.1175/15200450(1981)020<1145:ORPCAI >2.0.CO;2.

_ 1986: Rotation of principal components. J. Climatol., 6, 293 335, https://doi.org/10.1002/joc.3370060305.

Saji, N., B. Goswami, P. Vinayachandran, and T. Yamagata, 1999: A dipole mode in the tropical Indian Ocean. Nature, 401, 360 363, https://doi.org/10.1038/43854.

Song, D., Z. Guan, and W. Tang, 2011: Variations of OLR in Maritime Continent regions in association with droughts and floods in the upper and middle reaches of Yangtze River of China in boreal summer (in Chinese). J. Trop. Meteor., 27, 560-568.

Sukresno, B., 2010: Empirical orthogonal functions (EOF) analysis of SST variability in Indonesian water concerning with ENSO and IOD. Networking World Remote Sens., 38, 116-121.

Takaya, K., and H. Nakamura, 2001: A formulation of a phaseindependent wave-activity flux for stationary and migratory quasi-geostrophic eddies on a zonally varying basic flow. J. Atmos. Sci., 58, 608-627, https://doi.org/10.1175/15200469(2001)058<0608:AFOAPI > 2.0.CO;2.

Teo, C., T. Koh, J. C. Lo, and B. C. Bhatt, 2011: Principal component analysis of observed and modeled diurnal rainfall in the Maritime Continent. J. Climate, 24, 4662-4674, https:// doi.org/10.1175/2011JCLI4047.1.

Torrence, C., and G. P. Compo, 1998: A practical guide to wavelet analysis. Bull. Amer. Meteor. Soc., 79, 61-78, https://doi.org/ 10.1175/1520-0477(1998)079<0061:APGTWA > 2.0.CO;2.

Wakabayashi, S., and R. Kawamura, 2004: Extraction of major teleconnection patterns possibly associated with the anomalous summer climate in Japan. J. Meteor. Soc. Japan, 82, 15771588, https://doi.org/10.2151/jmsj.82.1577.

Wang, J., Z. Wen, R. Wu, Y. Guo, and Z. Chen, 2016: The mechanism of growth of the low-frequency East Asia-Pacific teleconnection and the triggering role of tropical intraseasonal oscillation. Climate Dyn., 46, 3965-3977, https://doi.org/ 10.1007/s00382-015-2815-7.

Wang, M., Z. Guan, and D. Jin, 2018: Two new sea surface temperature anomalies indices for capturing the eastern and central equatorial Pacific type El Niño-Southern Oscillation events during boreal summer. Int. J. Climatol., 38, 4066-4076, https://doi.org/10.1002/joc.5552.

Weng, H., S. K. Behera, and T. Yamagata, 2009: Anomalous winter climate conditions in the Pacific during recent El Niño Modoki and El Niño events. Climate Dyn., 32, 663-674, https://doi.org/ 10.1007/s00382-008-0394-6.

Wu, C. H., and H. Hsu, 2009: Topographic influence on the MJO in the Maritime Continent. J. Climate, 22, 5433-5448, https:// doi.org/10.1175/2009JCLI2825.1.

Xu, Q., and Z. Guan, 2017: Interannual variability of summertime outgoing longwave radiation over the Maritime Continent in relation to East Asian summer monsoon anomalies. J. Meteor. Res., 31, 665-677, https://doi.org/10.1007/s13351017-6178-3.

Zhang, C., 2005: Madden-Julian Oscillation. Rev. Geophys., 43, RG2003, https://doi.org/10.1029/2004RG000158.

— and Coauthors, 2010: MJO signals in latent heating: Results from TRMM retrievals. J. Atmos. Sci., 67, 3488-3508, https:// doi.org/10.1175/2010JAS3398.1. 